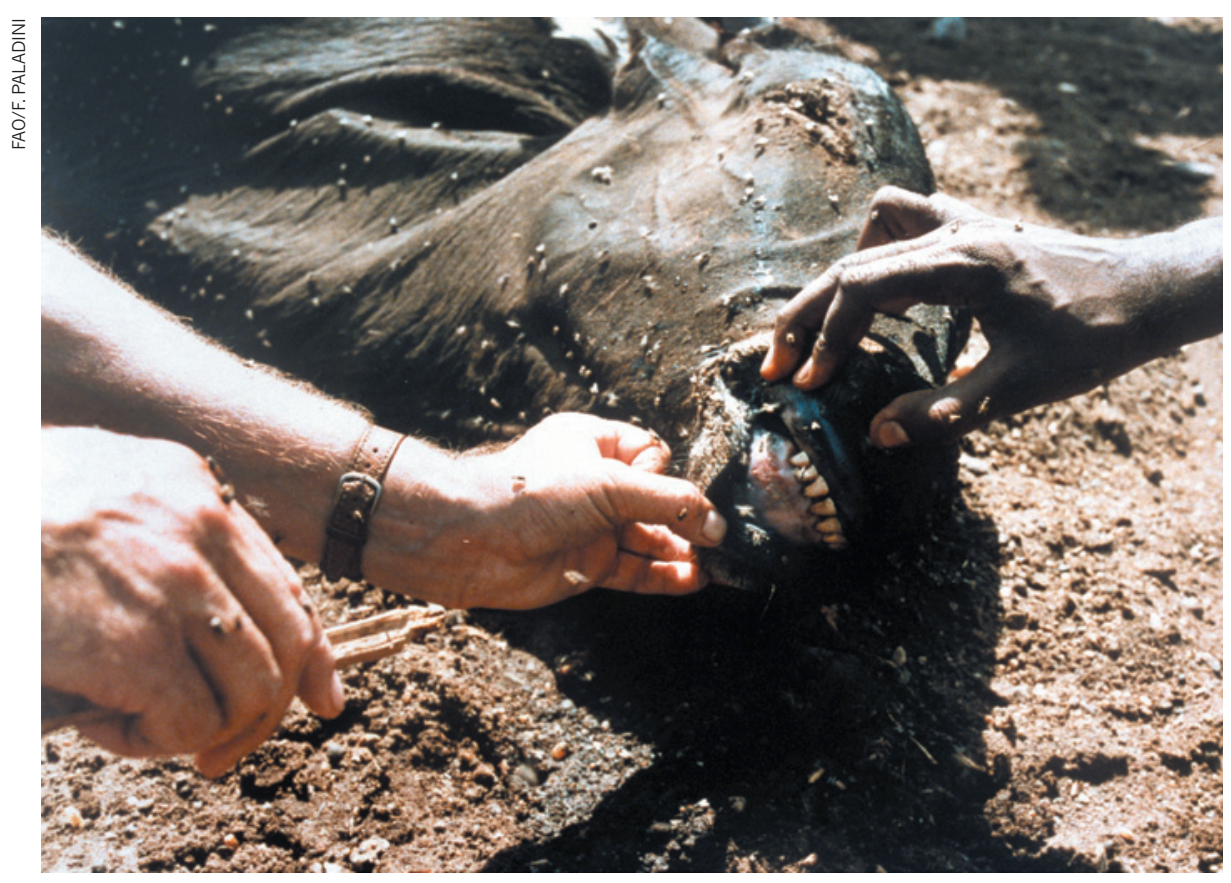

Mouth lesions are a sign of rinderpest, which has long decimated cattle throughout the world.

INFECTIOUS DISEASE

\title{
Officials act to secure cattle-plague virus
}

\section{Risk of accidental reintroduction shadows rinderpest eradication effort.}

\section{BY DECLAN BUTLER}

$\mathrm{R}$ inderpest, a devastating cattle disease, has not been seen in the wild for a decade, but it lives on in scores of labs. Twelve months after the world celebrated the success of a years-long vaccination campaign that made rinderpest only the second disease after smallpox to be eradicated, animal-health authorities are turning to the next task: making sure that a lab release - accidental or intentional - doesn't lead to a resurgence.

Rinderpest is as deadly to cattle as highly pathogenic H5N1 avian flu is to chickens. In past decades, outbreaks ripped through herds and wiped out up to $90 \%$ of animals, often leaving famine, and sometimes war, in their wake. "Its eradication is a huge, huge, achievement that has happened largely under the radar of most of the virology and scientific community," says David Ulaeto, a member of a seven-person multidisciplinary Joint Advisory Committee (JAC) on rinderpest that was set up to consolidate the eradication by the Romebased Food and Agriculture Organization of the United Nations (FAO) and the Paris-based
World Organisation for Animal Health (OIE). This October, the JAC will probably issue the first of a series of guidelines for an international oversight system. With the help of ad hoc expert groups, the JAC would approve official repositories of the virus and ensure that they meet tough biosafety standards. The committee would also approve all future research on live rinderpest virus to ensure that its benefits outweigh the risks.

The FAO and OIE don't have the authority to impose such measures on member states, but last year, countries gave the organizations a mandate by endorsing a moratorium on research and declaring that the remaining virus samples should be destroyed or shipped to approved high-security labs. The approach is modelled on the post-eradication phase of the smallpox campaign, which saw the number of labs holding the virus reduced from 76 in 1976 to just 2 in 1984.

To identify labs that might still hold rinderpest virus, the FAO carried out extensive literature searches, liaised $\rightarrow$ NATURE.COM To follow the last days of rinderpest, visit: go.nature.com/1kvnni with ministries of agriculture and veterinary services worldwide, and wrote "to virtually everyone they could think of", says Ulaeto. By last week, the FAO and OIE had identified some 40 labs. "They were a bit surprised at how many laboratories did have virus," he says.

The list remains confidential, but it includes labs from some 20 countries, thought to be mainly in Africa, the Middle East and Asia, where rinderpest outbreaks were common until recently, and a handful of established rinderpest research centres, such as the Institute for Animal Health in Pirbright, UK, and the Plum Island Animal Disease Center in New York state. One worrying aspect was that some virus samples were found to be held in facilities that had inadequate biosafety levels.

Fears of an accidental release are grounded in experience. After smallpox was eradicated, a lab accident in Birmingham, UK, resulted in two infections and one death. And an accidental release of foot-and-mouth virus from the Pirbright facility, which houses a highbiosecurity, world-reference laboratory for both foot-and-mouth and rinderpest, caused an outbreak in the United Kingdom in 2007.

Active research on rinderpest has waned as the disease has been brought under control over the past few decades, says Michael Baron, a rinderpest researcher at the Pirbright centre. He and others say that the biggest threat is from long-forgotten samples of virus from past research programmes, and serum and other samples collected for diagnostic or other purposes, that may be lurking in lab freezers. Rinderpest vaccine strains, which are stocked in many countries and consist of live attenuated virus, are also a concern. In theory, they could revert to wild type and cause disease outbreaks.

Until the world is certain that rinderpest is gone for good, vaccine strains will probably need to be maintained in high-security labs in several regions so that they can be shipped swiftly to any outbreak, says Baron. But he says that just a couple of pure-research labs would be enough to pursue the valuable scientific opportunities that rinderpest still offers.

Although the virus is closely similar to the human measles virus, for example, cattle don't catch measles and humans don't catch rinderpest. Understanding why this is so could provide insight into the pathology and basic biology of viruses, Baron says. Of more immediate interest, investigators would also like to know whether vaccines can be developed against another related virus, the sheep and goat disease called peste des petits ruminants, that might also protect against rinderpest. That would eliminate the need to keep any stocks of live attenuated rinderpest virus at all.

Baron's home lab contains more than 100 different rinderpest virus isolates, which he says represent "basically the history of the disease". He intends to sequence them all in the next few years - so that they can be recreated if ever needed - and then destroy them. 